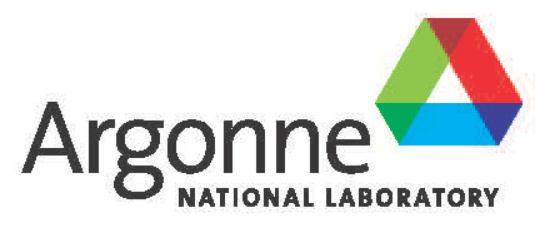

ANL/CSE-14/28

\title{
The Use of Eichrom's ABEC Resin for Technetium Removal from Potassium Molybdate Solutions
}

Chemical Sciences and Engineering Division 


\begin{abstract}
About Argonne National Laboratory
Argonne is a U.S. Department of Energy laboratory managed by UChicago Argonne, LLC under contract DE-AC02-06CH11357. The Laboratory's main facility is outside Chicago, at 9700 South Cass Avenue, Argonne, Illinois 60439. For information about Argonne and its pioneering science and technology programs, see www.anl.gov.
\end{abstract}

\title{
DOCUMENT AVAILABILITY
}

Online Access: U.S. Department of Energy (DOE) reports produced after 1991 and a growing number of pre-1991 documents are available free via DOE's SciTech Connect (http://www.osti.gov/scitech/).

Reports not in digital format may be purchased by the public from the National Technical Information Service (NTIS):

U.S. Department of Commerce

National Technical Information Service

5301 Shawnee Rd

Alexandria, VA 22312

unw.ntis.gov

Phone: (800) 553-NTIS (6847) or (703) 605-6000

Fax: (703) 605-6900

Email: orders@ntis.gov

Reports not in digital format are available to DOE and DOE contractors from the Office of Scientific and Technical Information (OST):

U.S. Department of Energy

Office of Scientific and Technical Information

P.O. Box 62

Oak Ridge, TN 37831-0062

unw.osti.gov

Phone: (865) 576-8401

Fax: (865) 576-5728

Email: reports@osti.gov

\section{Disclaimer}

This report was prepared as an account of work sponsored by an agency of the United States Government. Neither the United States Government nor any agency thereof, nor UChicago Argonne, LLC, nor any of their employees or officers, makes any warranty, express or implied, or assumes any legal liability or responsibility for the accuracy, completeness, or usefulness of any information, apparatus, product, or process disclosed, or represents that its use would not infringe privately owned rights. Reference herein to any specific commercial product, process, or service by trade name, trademark, manufacturer, or otherwise, does not necessarily constitute or imply its endorsement, recommendation, or favoring by the United States Government or any agency thereof. The views and opinions of document authors expressed herein do not necessarily state or reflect those of the United States Government or any agency thereof, Argonne National Laboratory, or UChicago Argonne, LLC. 


\section{The Use of Eichrom's ABEC Resin for Technetium Removal from Potassium Molybdate Solutions}

by

Megan E. Bennett, Dominique Stepinski, Seema R. Naik, and George F. Vandegrift Chemical Sciences and Engineering Division, Argonne National Laboratory

prepared for

U.S. Department of Energy, National Nuclear Security Administration, Office of Defense Nuclear Nonproliferation

October 2014 



\section{CONTENTS}

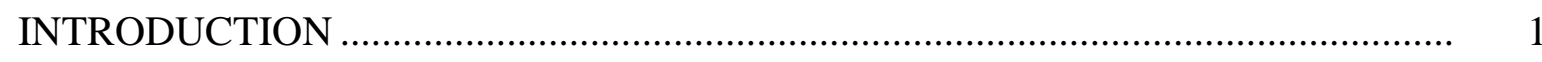

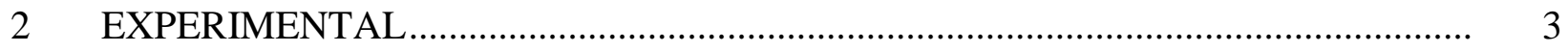

3 RESULTS AND DISCUSSION ................................................................. 4

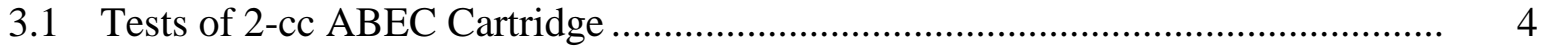

3.2 Tests of 10-cC ABEC Cartridge ......................................................................... 4

3.3 Tests of 25-cc ABEC Cartridge .................................................................... 5

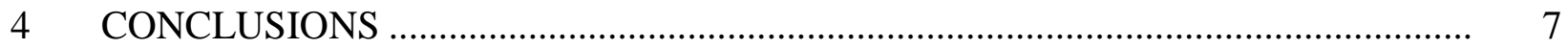

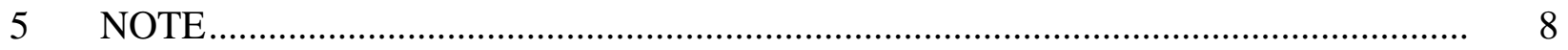

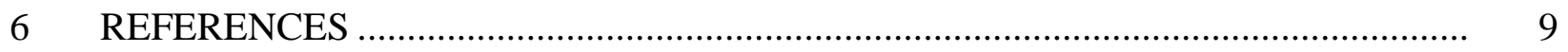

\section{FIGURES}

1 Breakthrough Curves for ${ }^{99}$ Tc on 2-cc ABEC Cartridges for Flow Rates Ranging from 2 to $30 \mathrm{~mL} / \mathrm{min}$

2 Breakthrough Curve for ${ }^{99}$ Tc on 10-cc ABEC Cartridges for Flow Rates of 10, 20 , and $30 \mathrm{~mL} / \mathrm{min}$.

3 The Breakthrough Curves for ${ }^{99}$ Tc on a 2-cc ABEC Cartridge for a Flow Rate of $10 \mathrm{~mL} / \mathrm{min}$ 
This page intentionally left blank 


\section{THE USE OF EICHROM'S ABEC RESIN FOR TECHNETIUM REMOVAL FROM POTASSIUM MOLYBDATE SOLUTIONS}

\section{INTRODUCTION}

More than $80 \%$ of nuclear medicine diagnostic tests or approximately 70,000 medical imaging procedures throughout the world daily use metastable technetium-99 $\left({ }^{99 \mathrm{~m}} \mathrm{Tc}\right)$ [1]. In 2009, it was reported that Canada's Chalk River research reactor and the Netherlands' High Flux reactor produce approximately 85\% of Europe's and North America's ${ }^{99}$ Mo supply [2]. It was recently announced that the Chalk River reactor will cease ${ }^{99}$ Mo production after 2016, creating a worldwide shortage of ${ }^{99}$ Mo unless reliable, alternative production methods are developed. Technetium-99m cannot be stockpiled because its parent isotope is molybdenum-99 ( $\left.{ }^{99} \mathrm{Mo}\right)$, which has a 66-hour half-life [3]. One possible production method is based on the $\left[{ }^{98} \mathrm{Mo}(\mathrm{n}, \gamma){ }^{99} \mathrm{Mo}\right]$ reaction pathway.

The typical reaction pathway for the production of ${ }^{99}$ Mo is neutron-induced fission of high-enriched uranium (HEU, $\geq 20 \%{ }^{235} \mathrm{U}$ ) in a nuclear reactor. After irradiation of the HEU target, the ${ }^{99}$ Mo is isolated from the uranium and other fission products, purified, and loaded onto a generator for delivery to radiopharmacies. The radiopharmacies then use the generator to separate the decay product or daughter, ${ }^{99 \mathrm{~m}} \mathrm{Tc}$, from the ${ }^{99} \mathrm{Mo}$. The ${ }^{99 \mathrm{~m}} \mathrm{Tc}$ has a 6-hour half-life and can be administered to patients on-site [4]. The production of ${ }^{99} \mathrm{Mo}$ with HEU is a nuclear proliferation concern, because HEU can be used in weapon manufacture. It is far more desirable

to produce ${ }^{99}$ Mo from either non-uranium-based sources, such as Mo irradiation, or low-enriched uranium (LEU, $<20 \%{ }^{235} \mathrm{U}$ ) [4]. The major downside of ${ }^{99}$ Mo production using non-HEU is that much more target material is needed, regardless of whether the reaction pathway uses Mo or non-HEU uranium, in order to synthesize an equal amount of Mo as obtained with HEU. Production using non-HEU methods, whether with a reactor or an accelerator, is greatly preferred because nuclear proliferation concerns are greatly reduced [5].

The reaction $\left[{ }^{98} \mathrm{Mo}(\mathrm{n}, \gamma){ }^{99} \mathrm{Mo}\right]$ is of interest, as it uses no uranium targets and presents no proliferation concern. After irradiation in the University of Missouri Research Reactor (MURR), the Mo target undergoes dissolution, which results in the Mo being in a final solution of $5 \mathrm{M}$ $\mathrm{KOH}$ and a volume of $1500 \mathrm{~mL}$. Upon receipt of the dissolution solution, it is desired to remove the Tc that has built up during irradiation from the solution so that it can be aliquoted and delivered to the radiopharmacies for immediate use. Eichrom Technologies, LLC, has developed ABEC, an extraction chromatographic resin specific for $\mathrm{TcO}_{4}{ }^{-}$, which is being used to purify the final dissolution solution.

Eichrom's ABEC resin consists of polyethylene glycols physisorbed onto an inert support. Eichrom has previously characterized the behavior of the pertechnetate ion $\left(\mathrm{TcO}_{4}{ }^{-}\right)$on ABEC resin in both batch studies and column studies at low flow rate $(<4 \mathrm{~mL} / \mathrm{min})$ [6-9]. Due to restrictions of commercial production, however, flow rates of $>10 \mathrm{~mL} / \mathrm{min}$ are necessary. In addition to this requirement, it is also necessary that all $1500 \mathrm{~mL}$ of solution be processed with the same ABEC cartridge. A successful process is defined by NorthStar Medical Radioisotopes 
as all post-ABEC cartridge aliquots $(29 \mathrm{~mL})$ containing $<30 \%$ of the possible Tc per pre-ABEC cartridge (the stock solution) aliquot $(29 \mathrm{~mL})$. The possible Tc per aliquot is defined as the total amount of Tc in $1500 \mathrm{~mL}$ divided by $1500 \mathrm{~mL}$ multiplied by the aliquot volume $(29 \mathrm{~mL})$. We investigated the performance of ABEC cartridges at flow rates ranging from 2 to $30 \mathrm{~mL} / \mathrm{min}$. 


\section{EXPERIMENTAL}

For this study, we used ABEC resin, available from Eichrom Technologies, LLC, in the form of pre-packed 2-cc cartridges. In addition to these, we tested 25- and 10-cc ABEC cartridges that had been wet-packed at NorthStar Medical Radioisotopes. We also used American Chemical Society (ACS) reagent-grade potassium hydroxide pellets and potassium nitrate crystals, as well as ACS reagent-grade molybdenum trioxide available from Acros Organics. An Ultima Gold XR liquid scintillation cocktail was obtained from Perkin Elmer. The ${ }^{99}$ Tc was originally in an ammonium pertechnetate chemical form and was obtained from Oak Ridge National Laboratory.

We prepared a stock solution of $\sim 200 \mathrm{~g} / \mathrm{L}(2.1 \mathrm{M}) \mathrm{Mo}$ as $\mathrm{MoO}_{3}, 5 \mathrm{M} \mathrm{KOH}, 0.1 \mathrm{M} \mathrm{KNO}_{3}$, and $18 \mathrm{M} \Omega$ deionized distilled water and filtered it through a $0.22 \mu \mathrm{m}$ polyethersulfone (PES) filter (available through Fisher Scientific). After the filtration, $\sim 170 \mu \mathrm{g}$ of ${ }^{99} \mathrm{Tc}$ was added to $1500 \mathrm{~mL}$ of the stock solution. It is expected that $170 \mu \mathrm{g}$ of total Tc is the upper limit of Tc at the end of irradiation of a natural-molybdenum target.

The ABEC resin columns were installed on a dispensing unit developed by NorthStar Medical Radioisotopes. The dispensing unit uses pressure to push eluents through the ABEC column. The column was conditioned with 10 bed volumes of $5 \mathrm{M} \mathrm{KOH}$. After conditioning, an aliquot of $29 \mathrm{~mL}$ of the stock solution, containing ${ }^{99} \mathrm{Tc}$, was passed through the ABEC cartridge, and a sample was collected from each 29-mL aliquot for liquid scintillation counting. Either 5 or 50 aliquots were passed over the resin, depending upon the experiment. After passing the appropriate number of aliquots over the resin, it was then stripped of Tc using $18 \mathrm{M} \Omega$ deionized water. Each set of experiments is discussed in further detail below. 


\section{RESULTS AND DISCUSSION}

\subsection{TESTS OF 2-CC ABEC CARTRIDGE}

We initially determined that, at a flow rate of $10 \mathrm{~mL} / \mathrm{min}$ with the 2-cc ABEC cartridge, $>30 \%$ of Tc breaks through after 5 aliquots. Subsequently, we passed 5 aliquots over the ABEC resin to evaluate flow rates from 2 to $30 \mathrm{~mL} / \mathrm{min}$. The breakthrough curves in Figure 1 show a clear division in the uptake of Tc on the ABEC resin according to the flow rate: little difference in the breakthrough curves from 2 to $10 \mathrm{~mL} / \mathrm{min}$, little difference in the data for flow rates between 15 to $30 \mathrm{~mL} / \mathrm{min}$, but a clear difference between these two groups. At flow rates $>10 \mathrm{~mL} / \mathrm{min}$, the breakthrough increases by more than $10 \%$. This increase is expected because as flow rate increases, the mobile phase has less residence time and thus less interaction with the stationary phase, resulting in higher breakthrough values. It is interesting that at increased flow rates of $15,20,25$, and $30 \mathrm{~mL} / \mathrm{min}$, the breakthrough of Tc is experimentally constant. This finding indicates that for applications where less Tc is present or smaller aliquot volumes are required, $A B E C$ is extremely robust and can be used at high flow rates. Use of even higher flow rates may also be possible in this application; however, a 2-cc cartridge is much too small to capture $>70 \%$ of the Tc present in a given aliquot. Due to production time restraints, a flow rate $\geq 10 \mathrm{~mL} / \mathrm{min}$ must be used; thus, lower flow rates will not be investigated further.

In addition to the results shown in Figure 1, we tested three 2-cc ABEC cartridges prepared with an improved washing procedure, as determined by NorthStar. The results showed that breakthrough occurred at aliquot 6 instead of aliquot 5 .

\subsection{TESTS OF 10-CC ABEC CARTRIDGE}

Initially, three 10-cc ABEC cartridges were tested by passing 50 aliquots over the ABEC resin at flow rates of 10,20 , and $30 \mathrm{~mL} / \mathrm{min}$. Figure 2 shows that only the column with a flow rate of $10 \mathrm{~mL} / \mathrm{min}$ met NorthStar's production requirement; thus, this rate was chosen for further investigation.

Based on the results presented above, 10 columns were tested at $10 \mathrm{~mL} / \mathrm{min}$ to evaluate their performance. All 10 columns failed to purify 50 aliquots of $\geq 70 \%$ Tc per sample. The columns failed at various aliquot numbers ranging from 18 to 47. Based on these results, it was determined that a fresh Mo solution would be used in all future experiments, and that NorthStar Medical would improve the ABEC cartridge packing procedure.

Six additional columns were prepared by an improved procedure and were run at $10 \mathrm{~mL} / \mathrm{min}$ with freshly made Mo solution (previous experiments reused the molybdate solution and adjusted the amount of Tc in the stock as necessary). Four of six of these columns failed to meet NorthStar's production requirement, failing at aliquot 30, 36, 26, and 27. One column successfully removed enough Tc, leaving $>4 \%$ Tc in aliquot 50 . 


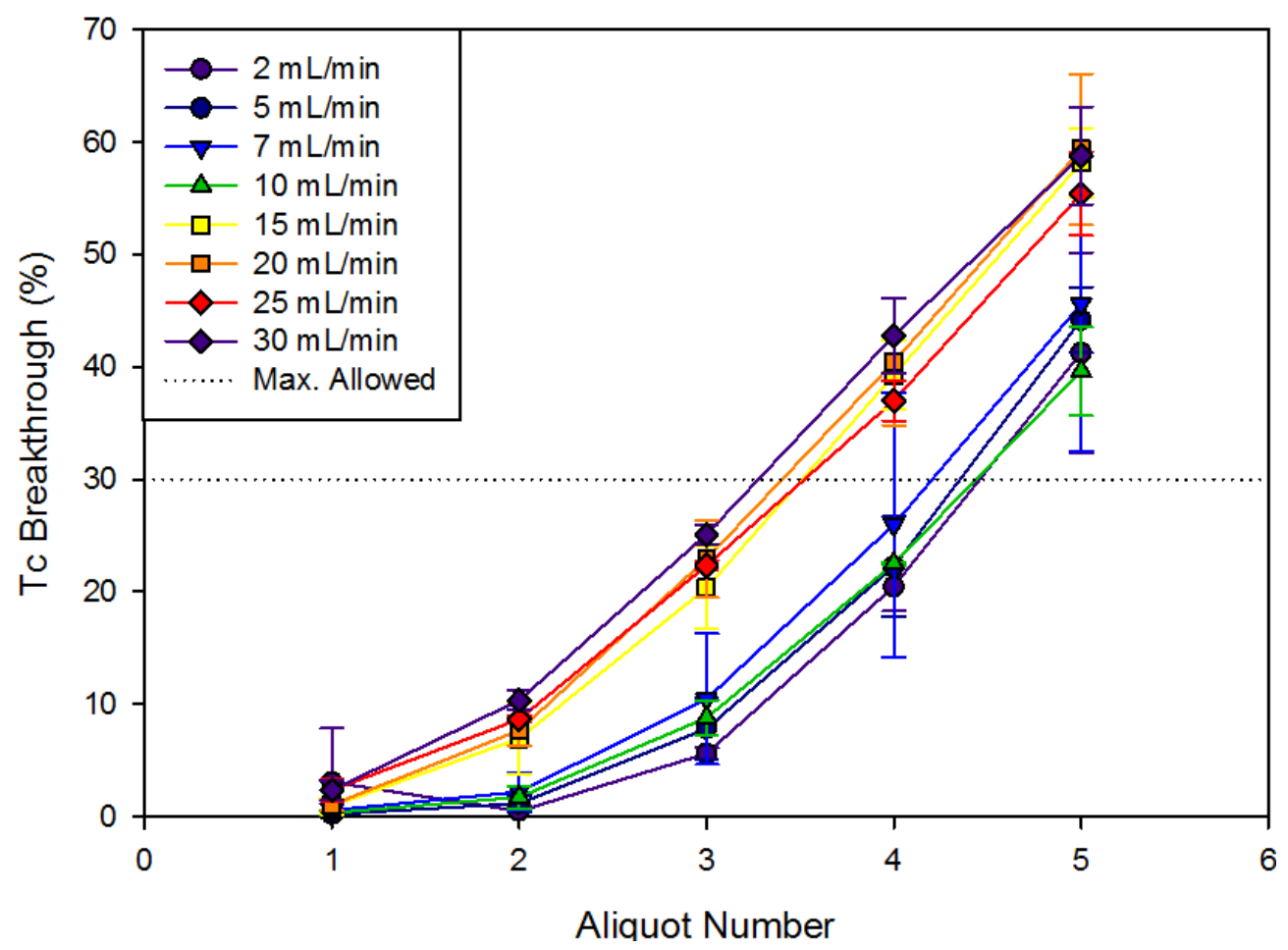

FIGURE 1 Breakthrough Curves for ${ }^{99}$ Tc on 2-cc ABEC Cartridges for Flow Rates Ranging from 2 to $30 \mathrm{~mL} / \mathrm{min}$. The percent breakthrough for each data point is the average breakthrough for the entire $29-\mathrm{mL}$ aliquot. Breakthrough of ${ }^{99} \mathrm{Tc}$ is clearly seen at flow rates $>10 \mathrm{~mL} / \mathrm{min}$. At aliquot 5 for flow rates $\leq 10 \mathrm{~mL} / \mathrm{min}$, as well as at aliquot 4 for flow rates $\geq 15 \mathrm{~mL} / \mathrm{min}$, the NorthStar specification (dotted horizontal line) fails to be met.

\subsection{TESTS OF 25-CC ABEC CARTRIDGE}

Two 25-cc cartridges were tested by passing 50 aliquots over the ABEC resin at a flow rate of $10 \mathrm{~mL} / \mathrm{min}$. One cartridge underwent NorthStar's improved ABEC washing procedure, and the other did not. The washed cartridge showed $0 \%$ Tc breakthrough on the column in the last aliquot, whereas the unwashed cartridge showed $3 \%$ Tc breakthrough in aliquot 50 . The data from the unwashed cartridge are shown in Figure 3. Based on these data, a 25-cc cartridge yields results that meet the needs of NorthStar, $\leq 30 \%$ Tc breakthrough in any sample. 


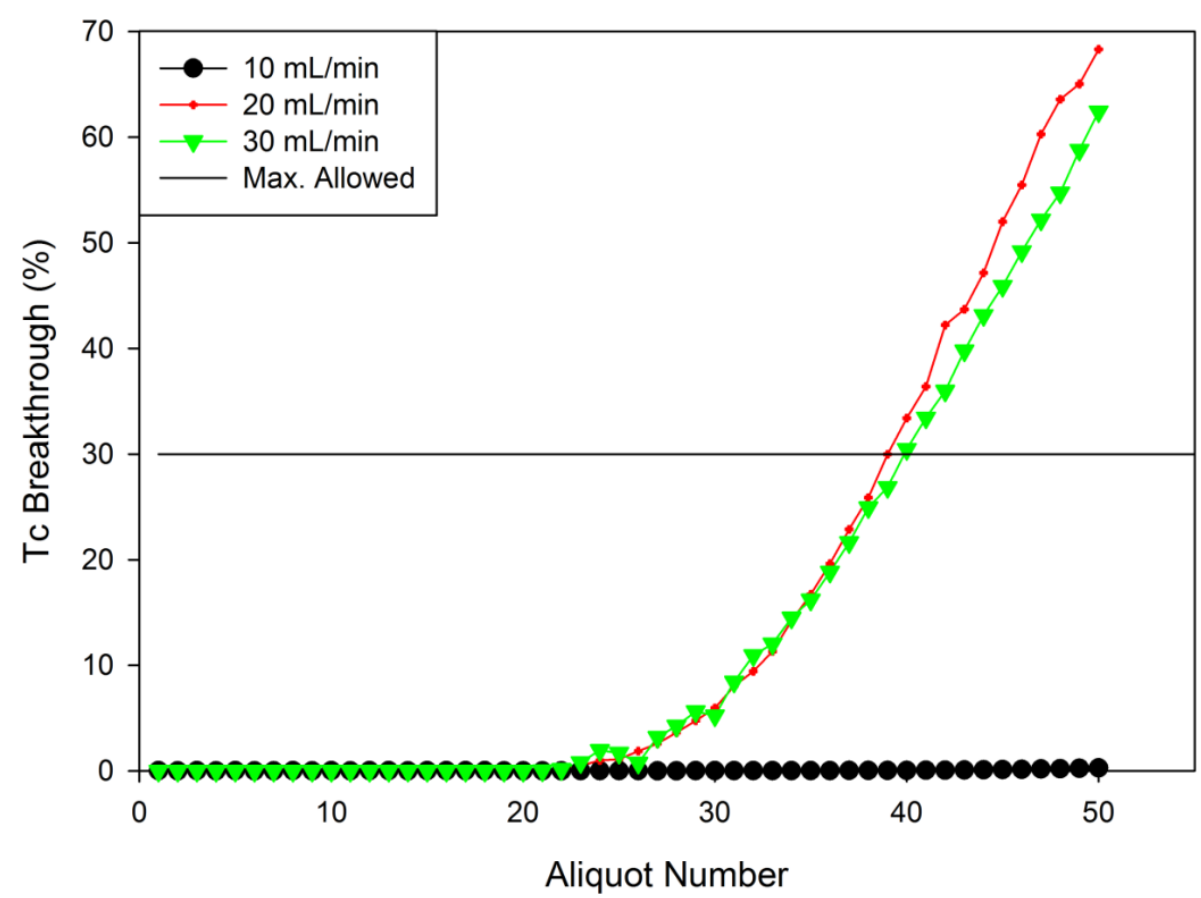

FIGURE 2 Breakthrough Curve for ${ }^{99}$ Tc on 10-cc ABEC Cartridges for Flow Rates of 10, 20, and $30 \mathrm{~mL} / \mathrm{min}$

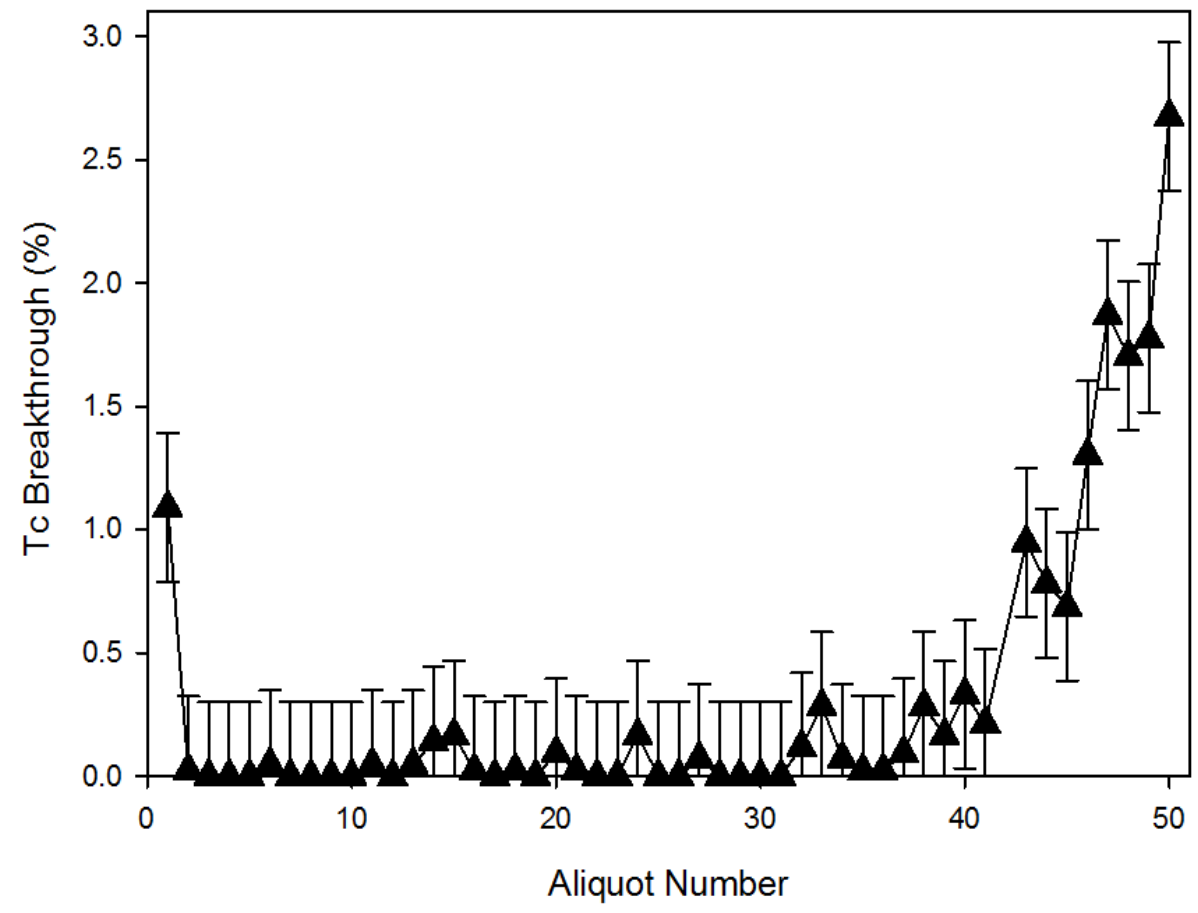

FIGURE 3 The Breakthrough Curves for ${ }^{99}$ Tc on a 25-cc ABEC Cartridge for a Flow Rate of $10 \mathrm{~mL} / \mathrm{min}$. Over the course of 50 samples, or $\sim 1500 \mathrm{~mL}$, all samples met the requirement of $<30 \%$ Tc in each aliquot. 


\section{CONCLUSIONS}

Columns of 2-, 10-, and 25-cc capacities have been tested. Based on the data obtained from 2-cc ABEC cartridges packed by Eichrom, we found that the uptake of Tc was unchanged, within experimental error, between 2 and $10 \mathrm{~mL} / \mathrm{min}$, as was the uptake of Tc between 15 and $30 \mathrm{~mL} / \mathrm{min}$. The uptake of Tc at the lower flow rates $(<10 \mathrm{~mL} / \mathrm{min})$ was approximately $10 \%$ higher than that of the higher flow rates $(>10 \mathrm{~mL} / \mathrm{min})$. These observations indicate that $\mathrm{ABEC}$ is a robust system with respect to flow rate, and the higher flow rates can be used. We also determined that 10 -cc cartridges do not have a large enough capacity to reproducibly remove $>70 \%$ Tc for all 50 aliquots, and that 2-cc cartridges seem best suited to fulfill this requirement.

Based on the above, we recommend that a batch study with the potassium molybdate solution be performed, and the VERSE code be used to determine the appropriate column size for removal of $>70 \%$ Tc in each of the 50 aliquots. A teleconference was held with NorthStar on September 11, 2014, and they agreed with this approach, which is now being pursued. 


\section{NOTE}

It was recently determined that, due to a miscommunication, the solution used in the experiments above was not the proposed feed solution for the actual process. The feed solution used in this study was $5.1 \mathrm{M} \mathrm{K}^{+}, 0.8 \mathrm{M} \mathrm{OH}^{-}, 0.1 \mathrm{M} \mathrm{NO}_{3}{ }^{-}, 2.1 \mathrm{M} \mathrm{MoO}_{4}{ }^{2-}$, and $113 \mu \mathrm{g} / \mathrm{L}^{99} \mathrm{Tc}$. The intended feed solution composition is $9.3 \mathrm{M} \mathrm{K}^{+}, 5.0 \mathrm{M} \mathrm{OH}^{-}, 0.1 \mathrm{M} \mathrm{NO}_{3}{ }^{-}, 2.1 \mathrm{M} \mathrm{MoO}_{4}{ }^{2-}$, and $113 \mu \mathrm{g} / \mathrm{L}{ }^{99}$ Tc. A new solution reflecting the intended solution is in the process of being prepared. Once this solution is prepared, a batch study and the VERSE code will be used to design an appropriate column. This column will then be tested. 


\section{REFERENCES}

[1] Gould, P., Nature 460: 312-313 (2009).

[2] Ruth, T., Nature 457: 536-537 (2009).

[3] National Research Council of Canada, “Solving Canada’s Medical Isotope Crisis,” http://www.nrc-cnrc.gc.ca/eng/achievements/highlights/2011/isotopes_ross.html, accessed December 2010.

[4] Moody, K.J., Hutcheon, I.D., and Grant, P.M., Nuclear Forensic Analysis, CRC Press, Boca Raton, FL (2005).

[5] Pillai, M.R.A., Dash, A., and Knapp, F.F., Jr., J. Nucl. Med. 54: 313-323 (2013).

[6] Rogers, R.D., Bond, A.H., Griffin, S.T., and Horwitz, E.P., Solvent Extr. Ion Exch. 14: 919-946 (1996).

[7] Rogers, R.D., Bond, A.H., Zhang, J., and Horwitz, E.P., Sep. Sci. Technol. 32: 867-882 (1997).

[8] Rogers, R.D., Griffin, S.T., Horwitz, E.P., and Diamond, H., Solvent Extr. Ion Exch. 15: 547-562 (1997).

[9] Bond, A.H., Chang, F.W.K., Thakkar, A.H., Williamson, J.M., Gula, M.J., Harvey, J.T., Griffin, S.T., Rogers, R.D., and Horwitz, E.P., Ind. Eng. Chem. Res. 38: 1676-1682 (1999). 
This page intentionally left blank 



\section{Argonne}

Chemical Sciences and Engineering Division

Argonne National Laboratory

9700 South Cass Avenue, Bldg. 205

Argonne, IL 60439-4837

www.anl.gov

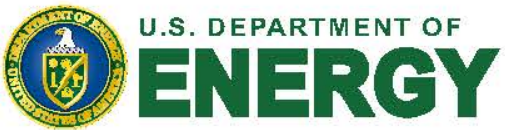

Argonne National Laboratory is a U.S. Department of Energy

laboratory managed by UChicago Argonne, LLC 